\title{
Noninvasive Preclinical and Clinical Imaging of Liver Transporter Function Relevant to Drug-Induced Liver Injury
}

\author{
J. Gerry Kenna, John C. Waterton, Andreas Baudy, Aleksandra Galetin, \\ Catherine D.G. Hines, Paul Hockings, Manishkumar Patel, \\ Daniel Scotcher, Steven Sourbron, Sabina Ziemian, and Gunnar Schuetz
}

\begin{abstract}
Imaging technologies can evaluate many different biological processes in vitro (in cell culture models) and in vivo (in animals and humans), and many are used routinely in investigation of human liver diseases. Some of these methods can help understand liver toxicity caused by drugs in vivo in animals, and druginduced liver injury (DILI) which arises in susceptible humans. Imaging could aid assessment of the relevance to humans in vivo of toxicity caused by drugs in animals (animal/human translation), plus toxicities observed using in vitro model systems (in vitro/in vivo translation). Technologies and probe substrates for quantitative evaluation of hepatobiliary transporter activities are of particular importance. This is due to the key role played by sinusoidal transporter mediated hepatic uptake in DILI caused by many drugs, plus the strong evidence that inhibition of the hepatic bile salt export pump (BSEP) can initiate DILI. Imaging methods for investigation of these processes are reviewed in this chapter, together with their scientific rationale, and methods of quantitative data analysis. In addition to providing biomarkers for investigation of DILI, such approaches could aid the evaluation of clinically relevant drug-drug interactions mediated via hepatobiliary transporter perturbation.
\end{abstract}

Key words Drug-induced liver injury, Drug labelling, Causality assessment, Hepatotoxicity, Hepatobiliary transporters, Bile salt export pump, Gadoxetate, Drug-drug interactions

\section{Introduction}

Many hundreds of different drugs cause liver injury in humans which occurs only infrequently and in certain susceptible individuals, and cannot be anticipated from nonclinical safety studies undertaken in vivo in experimental animals $[1,2]$. Hence their ability to cause human drug-induced liver injury (DILI) only starts to be appreciated in Phase 2 or Phase 3 clinical trials, or even postlicensing $[2,3]$. The consequences in affected patients may be marked symptomatic liver damage, or even acute liver failure, and currently it is not possible to predict and identify "at risk" patients 
prior to their exposure to the relevant drugs $[1,2]$. Because of this, unexpected "idiosyncratic" human DILI continues to be a leading cause of failed development of new drugs, of withdrawal from use of previously licensed drugs and of cautionary labeling that restricts prescribing [1-5].

The mechanisms by which drugs cause human idiosyncratic DILI are complex, and involve both drug-related adverse biochemical processes and susceptibility factors specific to susceptible patients $[1,2]$. Important drug-related adverse processes which can initiate idiosyncratic DILI include formation of chemically reactive metabolites, injury to mitochondria, and inhibition of the activity of the bile salt export pump (BSEP), which mediates efflux of toxic bile salts from hepatocytes into bile [6-8]. The susceptibility factors that explain why only some patients develop DILI are less well defined, although it is clear that these can include activation of both innate and adaptive immune responses [9].

Several of the key drug-related events that initiate idiosyncratic DILI can be quantified using various in vitro assays. These assays can be used during drug discovery, to enable early identification and deselection of compounds with high propensity to cause DILI and other serious adverse reactions [6-8]. Many different methodologies have been described, and are used routinely in pharmaceutical companies. They are discussed in Chap. 17 of this volume, by Light et al., and can reduce the likelihood that compounds progressed into clinical trials will cause DILI in humans. However, in vitro toxicity assays have several important limitations. The most commonly used in vitro toxicity assays fail to reproduce many of the key molecular events that influence hepatic drug uptake, biotransformation and excretion in vivo. Furthermore, the assays do not reproduce all of the mechanisms by which DILI occurs in vivo. Consequently, the precise relationship between potencies of effects observed in in vitro safety assays and functional consequences that may arise within the liver in vivo, and may result in DILI in susceptible drug exposed humans, remains poorly understood.

One approach which can help to address this important translational gap is medical imaging. Several imaging modalities can measure the hepatic uptake and clearance of probe substrates. Many are well suited to in vivo studies in animals and humans, while others can be utilized in cellular systems in vitro. Mechanistically relevant processes include the transporters that mediate drug uptake into and excretion from the liver, plus BSEP and other hepatobiliary transporters that mediate bile flow. Suitable imaging modalities and probe substrates are reviewed in Sect. 2. Key issues that need to be considered when generating reproducible data and undertaking quantitative analyses of imaging data are discussed in Sect. 3. These include assessing interaction between investigational drugs and the probe substrates used in imaging studies. Some of these interactions provide insight into undesired 
drug-drug interactions and this aspect is addressed in Sect. 4. An imaging approach to investigate and characterize liver injury with potential to provide novel insight into DILI risk is dynamic contrast-enhanced magnetic resonance imaging (DCE-MRI) using the contrast agent gadoxetate. This is reviewed in Sect. 5, which discusses the value and limitations of the approach. Finally, challenges and opportunities in using imaging technologies to understand and risk-manage DILI are considered in Sect. 6.

\section{Hepatobiliary Imaging Modalities and Tracers}

Imaging techniques can measure the appearance of probe substrates in different compartments (blood, hepatocyte, and bile) and, if imaging is repeated with high temporal resolution (the socalled dynamic imaging), then transporter kinetics can be inferred. The added value of spatially resolving the liver signal (as opposed to simply monitoring tracer disappearance from blood) was recognized over 60 years ago [10], although it is only recently that the uptake and elimination rates or kinetics have been employed to derive absolute kinetic rate constants. Hepatic uptake of drugs is mediated primarily by solute carriers expressed on the sinusoidal plasma membrane domain of hepatocytes and is an essential first step before DILI can be initiated. Consequently, data provided by imaging technologies which provide quantitative insights into hepatic uptake transporter kinetics has the potential to improve interpretation of the in vivo DILI relevance of in vitro toxicity assay data, which currently poses a major challenge (e.g., see Chaps. 6, 8, and 17). In addition, inhibition of the activity of the biliary efflux transporter BSEP plays a direct role in the mechanism by which numerous drugs can initiate DILI, while upregulation of the activity of other biliary efflux transporters plays an important hepatoprotective role in response to BSEP inhibition by drugs [11] (see also Chap. 15). Furthermore, a recent genetic analysis undertaken in a Chinese patient cohort has revealed an association between genetic variants in the gene encoding BSEP ( $A B C B 11)$ and cholestatic liver injury caused by treatment for between 6 and 9 months with antituberculous drugs (a combination of isoniazid, rifampicin, pyrazinamide, ethambutol, and/or streptomycin) [12]. Hence imaging methods that enable direct quantitative evaluation of drug-induced hepatic uptake and efflux transporter kinetics in vivo, and can be used to investigate perturbation of transporter function following administration of test drugs, have the potential to improve understanding of DILI mechanisms, and of DILI risk.

Several different imaging modalities can be used to assess hepatobiliary transporter kinetics (Table 1) [13]. A suitable imaging modality requires sufficient spatial resolution to resolve compartments, and adequate temporal resolution to enable characterization 


\section{Table 1}

\section{Imaging modalities used in liver transporter research in rats and humans [13]}

\begin{tabular}{|lllll}
\hline & $\begin{array}{l}\text { Typical region } \\
\text { electromagnetic } \\
\text { spectrum }\end{array}$ & $\begin{array}{l}\text { lonizing } \\
\text { radiation }\end{array}$ & $\begin{array}{l}\text { Tissue } \\
\text { depth }\end{array}$ & $\begin{array}{l}\text { Typical spatial } \\
\text { resolution/mm (human } \\
\text { liver; rat liver) }\end{array}$ \\
\hline $\begin{array}{l}\text { Magnetic resonance imaging } \\
(\mathrm{MRI})\end{array}$ & $63-500 \mathrm{MHz}$ & No & Full & $2 \times 2 \times 4 ; 0.2 \times 0.2 \times 2$ \\
\hline $\begin{array}{l}\text { Fluorescence or optoacoustic } \\
\text { Radiography and X-ray }\end{array}$ & $500-1000 \mathrm{~nm}$ & No & $20 \mathrm{~mm}$ & $-; 1 \times 1$ \\
\hline $\begin{array}{c}\text { computed tomography (CT) } \\
\text { Scintigraphy and single-photon } \\
\text { emission computed } \\
\text { tomography (SPECT) }\end{array}$ & $141-159 \mathrm{keV}$ & Yes & Full & $5 \times 5 \times 5 ; 0.5 \times 0.5 \times 0.5$ \\
\hline $\begin{array}{c}\text { Positron emission tomography } \\
\text { (PET) }\end{array}$ & $511 \mathrm{keV}$ & Yes & Full & $2 \times 2 \times 2$ \\
\hline
\end{tabular}

an the electromagnetic spectrum, a wavelength of $1 \mathrm{~m}$ corresponds to a frequency of $300 \mathrm{MHz}$ and an energy of $1.24 \times 10^{-6} \mathrm{eV}$

of kinetics. In addition, its signals must penetrate tissue to the depth of the liver in the species of interest (e.g., rat, human), and the modality must be able to detect exogenous substances which are transporter substrates. Ideally the imaging technology, and the substance detected, must also be widely available and of sufficiently low risk to allow studies to be performed in humans. Exogenous imaging substances used at high doses in imaging studies are called contrast media or contrast agents: these have the potential to saturate transporters. Conversely, exogenous imaging substances used in microdoses are called tracers. Many contrast agents and tracers will be discussed below, with priority given to those approved for human use as such approval demonstrates successful preclinical to clinical translatability for hepatobiliary function assessment.

Each modality exploits the different chemistry of the probe substances it detects [14]. Nuclear medicine modalities, i.e., positron emission tomography (PET) and single-photon emission computed tomography (SPECT)/scintigraphy, detect trace (subnanomolar) amounts of a substance radiolabeled with an isotope possessing a particular emission characteristic. SPECT studies detect gamma-emitting isotopes such as technetium-99m $\left(t_{1 / 2}=6 \mathrm{~h}\right)$ or iodine-123 $\left(t_{1 / 2}=13 \mathrm{~h}\right)$. PET studies detect positron-emitting isotopes such as carbon-11 $\left(t_{1 / 2}=20 \mathrm{~min}\right)$ or fluorine-18 $\left(t_{1 / 2}=110 \mathrm{~min}\right)$. CT and X-radiography can detect high micromolar or millimolar amounts of a heavy atom such as iodine in organoiodine contrast agents. MR can detect high micromolar or millimolar amounts of substances which accelerate the nuclear 
magnetic relaxation of water protons, such as gadolinium-chelate contrast agents. Fluorescence or optoacoustic imaging detects chromophores that emit visible or near-infrared light when excited by light of a specific wavelength. A final imaging modality, ultrasound, will not be discussed further as, although it is used clinically to evaluate hepatobiliary structures, there are no known chemistries that could generate hepatobiliary tracers suitable for ultrasound studies.

In principle, any adequately nontoxic substance with significant clearance through the liver can be used to measure liver transporter kinetics by imaging, provided that the substance is detectable using one of the imaging modalities in Table 1 and the mechanism of clearance is well understood. Since the 1920s, many tracers and contrast agents (Table 2, Fig. 1) have been developed specifically for medical imaging of the hepatobiliary system [15]. This allowed different medical imaging procedures to be devised, including radiographic visualization of the bile duct (cholangiography) and gall bladder (cholecystography), or visualization of the bile duct by SPECT and scintigraphy (cholescintigraphy) [16]. More recently, contrast agents have been developed for liver imaging via MRI, of which gadoxetate is most notable. Such agents are taken up by normal hepatocytes (but not neoplasms), and appear in the biliary tree. Quantitation of their uptake and biliary excretion provides an assessment of liver function [17, 18], and (through imaging) a functional liver volume. These tracers and contrast agents were optimized iteratively by medicinal chemists. For cholangiography, cholecystography, and cholescintigraphy, the ideal molecule reaches the biliary tree as a bolus requiring both very rapid uptake into the hepatocyte and very rapid elimination from the hepatocyte into the bile. However, for more modern applications such as detecting neoplasms and measuring functional liver volume) the ideal molecule is taken up rapidly into the hepatocyte but is eliminated rather slowly, to allow flexibility in the timing of imaging.

Few of the reported tracers and contrast agents are currently marketed. Others are or were investigational, or were formerly marketed then withdrawn (Table 2). From the perspective of an investigator planning a clinical imaging study on transporter function, a marketed agent is much more appealing than an investigational or withdrawn agent. The former (such as gadoxetate or mebrofenin) can be sourced readily from the pharmacy: ethical review would note off-label use of an approved medicinal product (with due consideration of radiation dose and other potential harms). On the other hand, use of a nonapproved agent (such as gadocoletic acid or arclofenin) would introduce many complications, requiring an IND (investigational new drug) application and establishing production according to Good Manufacturing Practice. It is for this reason that gadoxetate is of particular interest. 
Table 2

\section{Imaging tracers and contrast agents which are liver transporter substrates}

\begin{tabular}{|c|c|c|}
\hline $\begin{array}{l}\text { Modality: Chemical } \\
\text { class }\end{array}$ & Currently used in man & Investigational or formerly used \\
\hline $\begin{array}{l}\text { MRI: Gadolinium } \\
\text { chelate }\end{array}$ & $\begin{array}{l}\text { Gadoxetate (Primovist, } \\
\text { Eovist) } \\
\text { Gadobenate } \\
\quad \text { (Multihance) }\end{array}$ & Gadocoletate \\
\hline Fluorescence & $\begin{array}{l}\text { Indocyanine green } \\
\text { Fluorescein }\end{array}$ & $\begin{array}{l}\text { Bromosulfophthalein; tauro-nor-THCA-24-DBD; } \\
\text { 5-chloromethylfluorescein diacetate; } \\
\text { chloromethylfluorescein; dichlorofluorescein }\end{array}$ \\
\hline CT: Triiodophenyl & & $\begin{array}{l}\text { Bunamiodyl; iobenzamic acid;iocetamic acid; } \\
\text { iopanoic acid; ipodic acid; iophenoxic acid; } \\
\text { iopronic acid; tyropanote; iosumetic acid; } \\
\text { phenobutiodil; RCK-136 }\end{array}$ \\
\hline CT: Bistriiodophenyl & $\begin{array}{l}\text { Iodipamide } \\
\quad \text { (Cholografin) } \\
\text { Iotroxinate (Biliscopin) }\end{array}$ & $\begin{array}{l}\text { Iodoxamate; ioglycamic acid; iosefamate; } \\
\text { iosulamide }\end{array}$ \\
\hline $\begin{array}{l}\text { SPECT: }{ }^{99 \mathrm{~m}} \mathrm{Tc} \\
\text { iminodiacetic acid } \\
\text { conjugates }\end{array}$ & $\begin{array}{l}{\left[{ }^{99 \mathrm{~m}} \mathrm{Tc}\right] \text { disofenin }} \\
\text { (Hepatolite) } \\
{\left[{ }^{99 \mathrm{~m}} \mathrm{Tc}\right] \text { mebrofenin }} \\
\quad \text { (Choletec) }\end{array}$ & $\begin{array}{l}{\left[{ }^{99 \mathrm{~m}} \mathrm{Tc}\right] \text { arclofenin; }\left[{ }^{99 \mathrm{~m}} \mathrm{Tc}\right] \text { bultifenin; }\left[{ }^{99 \mathrm{~m}} \mathrm{Tc}\right] \text { etifenin; }} \\
\quad\left[{ }^{99 \mathrm{~m}} \mathrm{Tc}\right] \text { galtifenin; }\left[{ }^{99 \mathrm{~m}} \mathrm{Tc}\right] \text { iprofenin; }\left[{ }^{99 \mathrm{~m}} \mathrm{Tc}\right] \\
\text { lidofenin }\end{array}$ \\
\hline $\begin{array}{l}\text { SPECT: } \\
\text { Radioiodophenyl }\end{array}$ & & $\begin{array}{c}{\left[{ }^{131} \mathrm{I}\right] \text { iodipamide; }\left[{ }^{123} \mathrm{I}\right] \text { iodoxamate; }\left[{ }^{[31} \mathrm{I}\right] \text { ipodate; }} \\
{\left[{ }^{[31} \mathrm{I}\right] \text { ioglycamate; }\left[{ }^{131} \mathrm{I}\right] \text { rose bengal }}\end{array}$ \\
\hline $\begin{array}{l}\text { SPECT: }{ }^{99 \mathrm{~m} T \mathrm{c}} \\
\text { pyridoxal derivative }\end{array}$ & $\begin{array}{l}{\left[{ }^{99 \mathrm{~m}} \mathrm{Tc}\right]-N \text {-pyridoxyl-5- }} \\
\text { methyltryptophan }\end{array}$ & \\
\hline $\begin{array}{l}\text { PET: }\left[{ }^{11} \mathrm{C}\right] \text {-labeled } \\
\text { therapeutic drug or } \\
\text { metabolite }\end{array}$ & & $\begin{array}{l}{\left[{ }^{11} \mathrm{C}\right] \text { dehydropravastatin; }\left[{ }^{11} \mathrm{C}\right] \text { erlotinib; }\left[{ }^{11} \mathrm{C}\right]} \\
\text { metformin; }\left[{ }^{11} \mathrm{C}\right] \text { rosuvastatin; }\left[{ }^{11} \mathrm{C}\right] \mathrm{SC}-62807 ; \\
{\left[{ }^{11} \mathrm{C}\right] \text { telmisartan; }\left[{ }^{11} \mathrm{C}\right](15 \mathrm{R}) \text {-16-m-tolyl- }} \\
\quad 17,18,19,20 \text {-tetranorisocarbacyclin methyl ester }\end{array}$ \\
\hline $\begin{array}{l}\text { PET: }\left[{ }^{11} \mathrm{C}\right] \text {-labeled } \\
\text { bile acid derivative }\end{array}$ & & $\begin{array}{l}N \text { - }\left[\text { Methyl- }{ }^{11} \mathrm{C}\right] \text { cholylsarcosine; } N-\left[\text { methyl- }{ }^{11} \mathrm{C}\right] \\
\text { taurocholic acid; } N \text { - }[\text { methyl- }-11 \mathrm{C}] \text { taurolithocholic } \\
\text { acid; } N \text { - }\left[\text { methyl- }{ }^{11} \mathrm{C}\right] \text { tauroursodeoxycholic acid }\end{array}$ \\
\hline
\end{tabular}

References are cited in Sect. 2

2.1 Radiography and $\mathrm{CT}$
Radiography and CT have been used clinically to evaluate the hepatobiliary system, employing contrast agents that assess hepatocyte function. The contrast agents for radiography and CT incorporate one or two triiodophenyl moieties, providing respectively three or six heavy atoms (i.e., nonradioactive ${ }^{127} \mathrm{I}$ ) per molecule. Many such agents have been developed and marketed (see Table 2) in multiple jurisdictions, for cholangiography and cholecystography. These include iodipamide [19-21] and iotroxate [22]. These agents are cleared via the biliary system and, although there were early studies of transport of ipodate, iodipamide [23], and bunamiodyl [24], 
(a) $\left.{ }^{[99 \mathrm{~m}} \mathrm{Tc}\right]-M e b r o f e n i n$

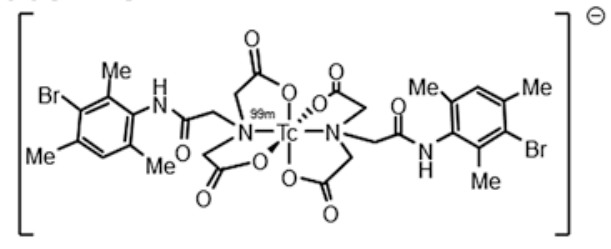

(c) lotroxate<smiles>O=C(COCCOCCOCC(=O)Nc1c(I)cc(I)c(C(=O)O)c1I)Nc1c(I)cc(I)cc1I</smiles>

(e) $\left[{ }^{11} \mathrm{C}\right]-\mathrm{N}$-methyl-cholylsarcosine

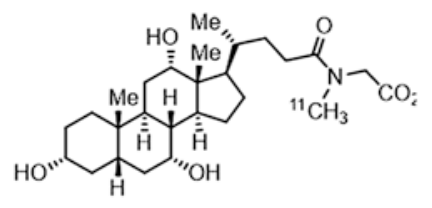

(b) Gadoxetate disodium

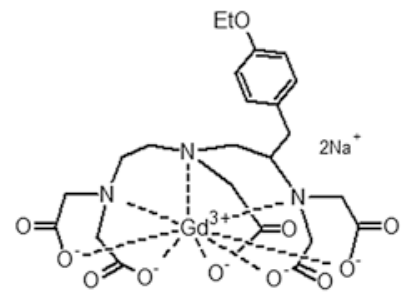

(d) $\left.{ }^{99 \mathrm{~m}} \mathrm{Tc}\right]-\mathrm{N}$-Pyridoxyl-5-methyltryptophan<smiles>Cc1ccc2[nH]cc(CC(Cc3cnc(C)c(O)c3CNC(=O)O)C(=O)O)c2c1</smiles>

(f) Indocyanine green

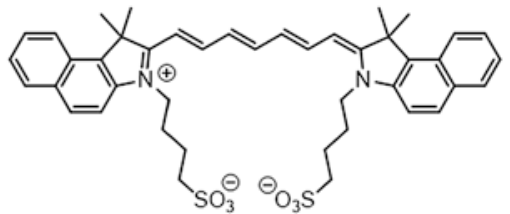

Fig. 1 Tracers and contrast agents used for liver transporter assessment in vivo. (a) [99mTc]-Mebrofenin (scintigraphy/SPECT). (b) Gadoxetate disodium (MRI). (c) lotroxate (radiography/CT). (d) [99mTC]-N-Pyridoxyl5-methyltryptophan (scintigraphy/SPECT). (e) $\left[{ }^{11} \mathrm{C}\right]-\mathrm{N}$-Methyl-cholylsarcosine (PET). (f) Indocyanine green (optical)

the clearance of biliary CT agents remains poorly understood [19] and does not yet provide specific information on liver transporters; rather, these tracers are used primarily for gross assessment of the biliary tract. Most have now been withdrawn from the market because of nephrotoxicity or lack of demand. However, iodipamide [25] and iotroxate [26] are still marketed in some jurisdictions.

2.2 MRI

Several gadolinium chelates have been rationally designed for liver MRI. These agents are detected in MRI because they are effective at enhancing the nuclear magnetic relaxation of water protons, i.e., they have high relaxivity.

Gadoxetate [27] and gadobenate [28], which undergo partial hepatocyte-mediated elimination, are approved for use in multiple jurisdictions. Gadoxetate is FDA-approved for detection and characterization of focal liver lesions and exhibits high biliary clearance. Gadoxetate also has affinity for various liver transporters in multiple species (human OATP1B1, OATP1B3, MRP2, and NTCP; rat OATPlal, Mrp2, Mrp3, and OatplA2) [29-32], and has been used preclinically and clinically to investigate liver transporter dysfunction or inhibition that may decrease hepatobiliary function or 


\subsection{Scintigraphy and SPECT}

cause cholestatic injury $[32,33]$. This area of research is developing rapidly and is discussed further in Sect. 4.

Mangafodipir, a manganese chelate, was previously used for detection of liver lesions: it releases $\mathrm{Mn}^{2+}$ which is taken up by functioning hepatocytes [34, 35] through calcium channels, although the exact transporters and channels are not known. It is no longer marketed.

Fortuitously, iodine has several radioactive isotopes suitable for scintigraphy/SPECT (iodine-123, and formerly iodine-131 which is no longer used to high $\beta$ radiation) or PET (iodine-124). Several of the triiodophenyl-based radiographic contrast media have also been synthesized with radioiodine for nuclear medicine: indeed, the first imaging agent used for hepatobiliary function was $\left[{ }^{131} \mathrm{I}\right]$ rose bengal [10]. Use of SPECT or PET rather than CT is advantageous, as the high doses of contrast agent required for $\mathrm{CT} /$ radiography may be nephrotoxic, while PET and SPECT tracers are used at much lower doses and hence incur no risk beyond the ionizing radiation. Subsequently, ${ }^{99 \mathrm{~m}} \mathrm{Tc}$-chelate-based cholescintigraphy tracers were rationally designed [36]. The most important series incorporates an iminodiacetic acid ${ }^{99 \mathrm{~m}} \mathrm{Tc}$-chelate. Of these, [ ${ }^{99 \mathrm{~m}} \mathrm{Tc}$ ] mebrofenin [37] and disofenin [38] are marketed in some jurisdictions. An alternative technetium chelate chemistry uses pyridoxal derivatives [39]: $\left[{ }^{99 \mathrm{~m}} \mathrm{Tc}\right] N$-pyridoxyl-5-methyltryptophan $\left(\left[{ }^{99 \mathrm{~m}} \mathrm{Tc}\right] \mathrm{PMT}\right)[40,41]$ is used clinically in Japan. Human hepatic uptake of $\left.{ }^{99 \mathrm{~m}} \mathrm{Tc}\right] \mathrm{PMT}$ is mediated by OATP1B1 and OATP1B3, while its efflux into bile is via MDRl and MRP2 [42]. [99m Tc] mebrofenin is used in assessment of liver function and functional liver volume before and after surgery and has also been used to investigate hepatobiliary transporter dysfunction in vitro and in vivo $[43,44]$. [ $\left.{ }^{99 \mathrm{~m}} \mathrm{Tc}\right]$ mebrofenin is almost exclusively taken up into the liver by OATPIBI and OATPIB3 and is excreted into the bile primarily by MRP2 [44-46].

$\left[{ }^{99 \mathrm{~m}} \mathrm{Tc}\right]$ sestamibi is marketed in several jurisdictions for assessment of myocardial function, and also has been used in vitro to study basolateral efflux [46]. [ $\left.{ }^{99 \mathrm{~m}} \mathrm{Tc}\right]$ sestamibi likely enters hepatocytes passively and undergoes partial fecal clearance, as efflux is modulated by hepatocyte P-gp and the tracer undergoes preferential basolateral efflux into the bile. [ ${ }^{99 \mathrm{~m}} \mathrm{Tc}$ ] galactosyl-human serum albumin is also used in Japan $[17,47]$ to assess liver function, but is not a known transporter substrate.

Gadolinium has a gamma-emitting isotope (gadolinium-153), so gadolinium-chelates can be detected using scintigraphy/ SPECT, although the rather long half-life of this isotope $\left(t_{1 / 2}=270 \mathrm{~d}\right)$ restricts its use to animal studies [48].

More recently, specific transporter-targeted positron-emitting tracers have been synthesized and used in animals or man, with particular emphasis on hepatobiliary transporters, although none 
has yet gained regulatory approval for use as a diagnostic product. Several of these (Table 2) are carbon-11 versions of small molecule drugs or drug metabolites which are known liver transporter substrates (e.g., erlotinib [49]; metformin [50], rosuvastatin [51], dehydropravastatin [52], telmisartan [53], and celecoxib metabolite [54]). ${ }^{11} \mathrm{C}$-labeled bile acid derivatives have also been synthesised, such as $\left[{ }^{11} \mathrm{C}\right]$ cholylsarcosine $[55-57]$; these have been used to investigate the kinetics of hepatobiliary tracer uptake and secretion in healthy pigs and humans in vivo, and to quantify perturbations that occur in patients with cholestasis.

\subsection{Fluorescence}

Fluorescent tracers offer the ability to image hepatobiliary processes at a cellular resolution and in real time, thereby granting opportunities to gain insights into detailed mechanistic perturbations of drugs on a high throughput level. Therefore they are well suited to in vitro studies of isolated cells or cell aggregates that can be imaged directly, although in general they are not appropriate for in vivo studies of cells within the liver or other internal organs. Methodologically, direct immunofluorescent antibody-based imaging of multiple transporters can answer whether the total amount of protein or localization (e.g., downregulation or receptor internalization) has occurred (e.g., $[58,59]$ ), whereas studies undertaken with fluorescein analogues and fluorescently tagged bile acid derivative probes enable kinetic measures of uptake and efflux transport rates.

Each fluorescent probe has its own characteristic transporter substrate affinity, which may vary depending on the species and complexity of the transport system that is investigated. Cholyllysyl-fluorescein (CLF), a bile acid analogue, is a particularly widely used probe, with data that have spanned in vitro and in vivo studies involving both animals and humans. CLF is an OATP1B3, MRP2, and MRP3 substrate [60]. Measurement of drug inhibition of CLF transport has been used to discern cholestatic mechanisms $[61,62]$, and a positive association has been demonstrated between cholestatic DILI in humans and inhibition of apical CLF efflux from rat hepatocytes in sandwich culture [63]. Moreover, CLF has been shown to have $100 \%$ sensitivity when used to detect liver cirrhosis in patient cohorts $[64,65]$.

Additional fluorescent substrates have also been developed for examining specific uptake and efflux transporter routes. Sodium fluorescein is an OATP1B1, OATP1B3, and MRP2 substrate and has been used effectively in vivo to study impaired hepatic transport in animals [66]. Similarly, a fluorescent bile acid derivative ( $\mathrm{N}-(24-$ [7-(4- N, N-dimethylaminosulfonyl-2,1,3-benzoxadiazole)]amino$3 \alpha, 7 \alpha, 12 \alpha$-trihydroxy- 27 -nor- $5 \beta$-cholestan-26-oyl)- $2^{\prime}$ aminoethanesulfonate) may be used to investigate NTCP-mediated uptake in both primary rat and human hepatocyte suspensions, and apical efflux from hepatocytes cultures in sandwich configuration 
which is presumed to be mediated by BSEP [67]. 5-Chloromethylfluorescein diacetate, a fluorescein analog, is an example of a reagent that can freely diffuse into hepatocytes and is then metabolized to glutathione methylfluorescein, a cell-impermeant fluorescent product and Mrp2 substrate [68]. Finally, 5-(and 6)-carboxy-2',7'dichlorofluorescein has been used to quantify Mrp2 efflux from primary rat hepatocytes cultured in sandwich configuration, and inhibition of this process by drugs and their metabolites [69]. Interestingly, such reagents can also be used alone or in combination with bright field time course imaging to study the dilation and constriction dynamics of the bile canaliculi, which have recently been shown to be altered by cholestatic drugs [70].

Indocyanine Green (ICG) is transported by OATP1B3 and NTCP [45], and is established for estimating global liver function. Feng et al. [71] demonstrated improved accuracy of predicting 3 -month mortality in acute liver failure patients, using a combination of ICG clearance measured with a pulse spectrometer and the model-for-end-stage liver disease (MELD) score, when compared to conventional scores. Subsequently, this result was extrapolated further to develop a human ex vivo model for acetaminopheninduced liver injury, in which ICG clearance was used as the outcome measure [72]. While probes that are more specific for liver transporter dysfunction have been reported, ICG is still used relatively routinely and has been approved for in vivo measurement of human hepatic function [73].

\section{Quantitative Analyses of Hepatic Imaging Data}

\subsection{Absolute Quantification of Hepatocellular Transporter Expression with Dynamic Imaging}

Imaging approaches to quantifying transporter expression follow the principles of standard pharmacokinetic measurements [74]. A suitable probe indicator (Sect. 2 ) is injected into the bloodstream and its concentration " $c$ " in a tissue of interest is measured as a function of time " $t$ " ( $\mathrm{min})$. The temporal structure of these concentration-time profiles is then interpreted using kinetic models of the motion of indicator molecules through tissue compartments (blood, interstitium, cells, bile, etc.).

Two different types of parameter can be derived from such dynamic imaging experiments $[75,76]$. The distribution volumes " $\mathrm{v}$ " $(\mathrm{ml} / \mathrm{g})$ measure the space $(\mathrm{ml})$ occupied by the indicator inside the compartments in a unit $(\mathrm{g})$ of tissue (examples are plasma, interstitial, and intracellular distribution volumes). The transfer constants " $k$ " ( $\mathrm{ml} / \mathrm{min} / \mathrm{g})$ measure the indicator flux ( $\mathrm{mmol} /$ $\mathrm{min} / \mathrm{g}$ ) out of a compartment per unit concentration " $c$ " $(\mathrm{mM})$. For instance, if $c_{\mathrm{i}}$ is the indicator concentration in the interstitium, then the indicator flux from interstitium to intracellular space is $k_{\mathrm{hi}} c_{\mathrm{i}}$. Physiologically, $k_{\mathrm{hi}}$ is the volume of interstitial fluid $(\mathrm{ml})$ in a unit of tissue $(\mathrm{g})$ that is cleared of indicator in a minute. At the low 
concentrations that are used in imaging experiments it is assumed that the transfer constants are not concentration-dependent (linearity). Other parameters can be derived from the transfer constants, such as the hepatic extraction fraction (\%), i.e., the percentage of indicator molecules that is extracted from the blood stream in one pass through the liver [77].

An accurate measurement requires at least two different concentration-time curves. One is the tissue concentration $c(t)$, which may be measured over the entire liver, an individual lobe, a liver segment, a smaller region within a segment or even a single imaging voxel ( $=3 \mathrm{D}$ pixel). The second curve, the input function, is measured in the arterial or portal venous inlet to the liver. Input functions are required as a reference to eliminate effects of systemic changes in the circulation, or differences in the way the tracer is injected. In measurements that also target perfusion, arterial and portal venous input functions are both required to separate out their individual contributions. In some cases outlet data are needed-in particular for indicators that are excreted from hepatocytes through biliary and interstitial routes.

The technical details of the image acquisition have a strong effect on parameter accuracy, but choosing the right approach involves trade-offs between accuracy, precision, practicality and cost. For instance, at higher sampling rates more rapid processes can be resolved, but this comes at a cost of image resolution and organ coverage. Equivalently, very long data collections ( $>45 \mathrm{~min}$ ) are required to characterize slow processes such as biliary excretion, but this has significant implications on patient comfort and scan costs. Another important consideration in the liver is to minimize the effect of breathing motion, which is detrimental to image quality [78]. The best compromise depends critically on the exact purpose of the measurement and requires careful applicationspecific optimization.

3.2 Semiquantitative Imaging Analysis
Clinical evaluation of gadoxetate-enhanced MRI is based on evaluation of imaging features such as observation size, presence of arterial phase hyper- versus hypo- or iso-enhancement, washout appearance, capsule appearance, and threshold growth [79]. Quantitation of the disposition of the contrast agent can be undertaken by calculation of maximum relative enhancement (RE) when compared with pre-contrast images [29] and measurement of area under the curve (AUC) of the liver enhancement. In addition, curve fitting of the intensity profile in the liver after a bolus injection of contrast agent enables estimation of kinetic parameters which include rate of hepatic wash-in and wash-out, and hepatic extraction fraction [80]. These descriptive analysis techniques can exhibit good signal-to-noise ratio and low variance at individual sites in comparison to the compartmental modeling techniques described in the previous section. However, the results often dis- 
play a greater dependence on experimental parameters, making comparisons between sites difficult and they lack direct relationship to transporter function that can provide additional and useful insights into pharmacologically and toxicologically relevant effects which otherwise may be difficult to obtain. For example, inhibition of hepatobiliary efflux transporters at the apical plasma membrane domain of hepatocytes membrane may lead to changes in drug exposure in the hepatocyte that have potential toxicological significance, but result only in minor changes in drug plasma exposure [81] (see also next section).

\section{Hepatobiliary Transporter Mediated Drug-Drug Interactions}

Hepatocytes express a range of transporter proteins mediating either active uptake of drugs/endogenous compounds from the blood (e.g., OATP1Bl, which is expressed on the basolateral plasma membrane domain) or their active secretion into the bile (e.g., BCRP, expressed on the apical plasma membrane domain) [82, 83]. Characterization of drug transporters in the liver (also in the intestine, kidney and brain) and their effect on drug pharmacokinetics and drug-drug interaction (DDI) risk is now an integral part of drug development, and is required by regulatory agencies [84-86]. P-gp (MDRl/ABCBl), BCRP, OATPlBl, OATP1B3, OATl, OAT3, and OCT2 are currently identified as key transporters for screening in drug development, with increased recognition of the clinical relevance of other transporters (e.g., MATE, BSEP, and OATP2B1) $[87,88]$. Increasingly, clinical evidence raises concerns about transporter-mediated DDIs, where changes in drug exposure in blood or plasma (commonly used as metric) may not be reflective of the changes in the tissue/cellular drug exposure (local DDI) that may have consequences on drug safety and efficacy. For example, modulation of OCT/MATE transporters has resulted in minimal or no changes in metformin systemic exposure in a number of cases, yet modified glucose lowering effect was reported (which was attributed to modified liver exposure to metformin) [88].

In addition to the important role of transporters, hepatic drug exposure may be influenced by passive diffusion through biological membranes, intracellular binding, metabolism and organelle sequestration (Fig. 2) [82]. In recent years, a range of cellular systems have been used to characterize complex interplay of these processes in vitro. These range from transporter-transfected cell lines to three-dimensional microphysiological systems; although the utility of the latter as a tool for quantitative in vitro metabolism/transporter evaluation and in vitro/in vivo translation is yet to be established [89-91]. Characterization of transporter-metabolism interplay in these holistic in vitro systems is supported by mechanistic modeling of in vitro data, which allows estimation of 

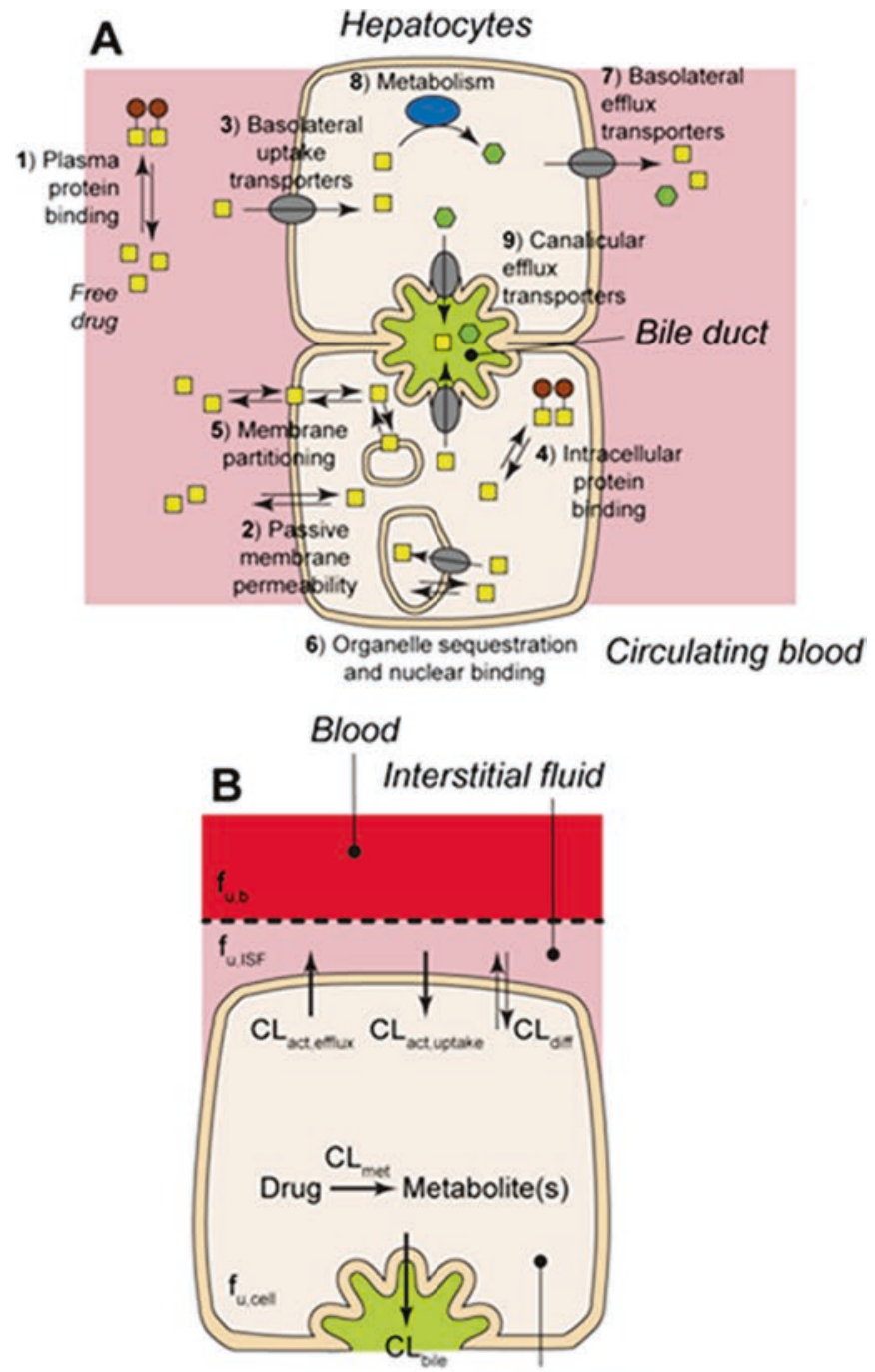

Hepatocyte

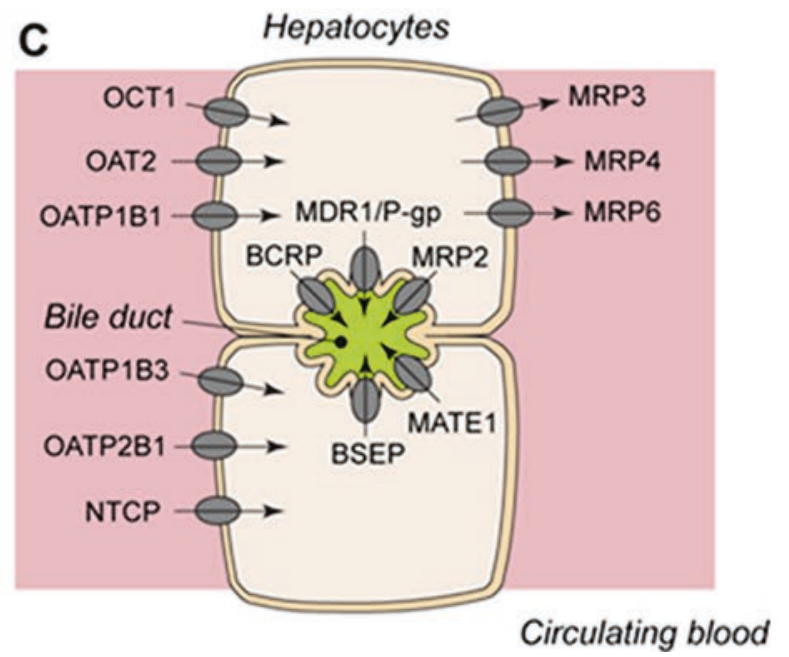

Fig. 2 Processes affecting intracellular drug concentration in the hepatocyte [82] 
transporter kinetic parameters (e.g., $K_{\mathrm{m}}, V_{\max }$, and $k_{\mathrm{i}}$ ) to be used subsequently for translational purposes in physiologically based pharmacokinetic (PBPK) models [92-94].

One of the key advantages of PBPK modeling is the ability to simulate and interpret concentration-time profiles in the tissues of interest (in addition to plasma). This modeling approach is extremely useful to improve our understanding of the ratedetermining process driving hepatic exposure of a drug, i.e., whether this is uptake, efflux/metabolism or a composite of multiple processes. It also provides mechanistic insight into in vivo consequences that arise when individual disposition processes are perturbed [81, 82, 94-97]. For example, active uptake via OATPs from the blood into hepatocytes is the major process leading to high unbound liver-blood concentration ratio of many statins (e.g., simvastatin acid). In such cases, reduced activity in OATP1B 1 transporter (due to either transporter inhibition or polymorphism) results in increased systemic exposure of simvastatin acid and increased risk of myopathy [95] (see Fig. 3). For drugs predominantly eliminated via liver, the effect of reduced OATP activity on liver exposure $\left(\mathrm{AUC}_{\text {liver }}\right)$ is expected to be marginal, as this parameter is determined primarily by either metabolic clearance (in case of simvastatin acid) or biliary excretion (BCRP-rosuvastatin, MRP2-pravastatin) [81, 82, 95-98]. In contrast, inhibition of biliary transporters (MRP2, BSEP) or metabolic enzymes (CYP3A4) may lead to changes in drug exposure in the liver and consequently even to hepatotoxicity, with only minor changes in drug plasma exposure. Verification of these PBPK model-predicted changes in tissue exposure is challenging. In the case of statins, clinical data provide indirect evidence to support this, as enhanced cholesterol reduction (associated with higher liver exposure of simvastatin) was reported in DDI studies with CYP3A4 inhibitors [95]. For certain drugs (e.g., repaglinide) delineation of the rate limiting step is
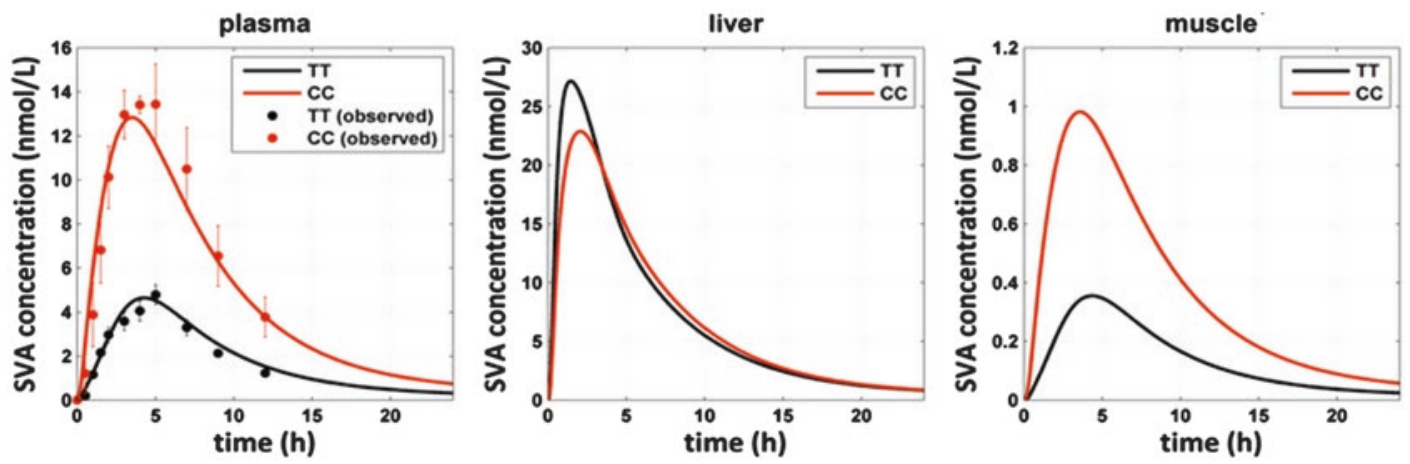

Fig. 3 Simulated concentration-time profiles for simvastatin acid (SVA) in plasma, liver tissue and muscle tissue for individuals with the homozygous wild-type TT (black line) and homozygous variant CC (red line) SLC01B1 c.521T $>C$. Full symbols represent observed mean \pm SE plasma SVA concentrations for individuals with the TT (black circles) and CC (red circles) genotype [95] 
not as straightforward as in the case of simvastatin acid, as hepatic disposition is a composite of multiple contributing processes. Drugs like repaglinide highlight the utility of PBPK modeling to gain mechanistic insight into interplay of processes and prediction of DDI risk [97].

In all the cases above, quantification of drug exposure in the liver (and other tissues) is crucial to support modeling and simulation efforts. Emerging data on tissue concentrations obtained by advanced imaging methods $[33,99]$, in conjunction with mechanistic PBPK modeling, is envisaged as a powerful tool to improve predictability and understanding of implications of transportermediated tissue distribution and interactions.

\section{Liver Imaging with Gadoxetate}

5.1 Current Clinical Use of Gadoxetate in Liver Disease Diagnosis
The disodium salt of gadoxetic acid (gadoxetate, gadoliniumethoxybenzyl-diethylenetriaminepentaacetic acid, SH L569 B, Gd-EOB-DTPA) is marketed by Bayer as Primovist ${ }^{\circledR}$ in Europe and Japan and as Eovist ${ }^{\circledR}$ in the USA and has been clinically approved as a liver-specific contrast agent for detection of focal liver lesions by magnetic resonance imaging. Gadoxetate exhibits a favorable safety profile [29, 100-104]. It has been demonstrated that gadoxetate does not trigger nephrogenic systemic fibrosis (NSF), even in the presence of moderate to severe renal impairment $[105,106]$, as a result of its dual excretion pathway. Recently, trace amounts of gadolinium have been detected in the brain of patients after several injections of the linear gadolinium-containing contrast agents gadodiamide, gadopentetate dimeglumine, gadobenate dimeglumine, and gadoversetamide. For gadoxetate, one report has indicated a correlation between the number of prior gadoxetate administrations and increase signal on nonenhanced Tl-weighted images in the dentate nucleus [107], while a second report did not find such a correlation [108]. Currently it is not known whether persistence of gadolinium in the brain following therapeutic administration of contrast agents is associated with adverse health consequences.

Gadoxetate combines the well-established imaging characteristics of extracellular nonspecific gadolinium contrast agents during dynamic phases with further imaging information during the hepatobiliary disposition phase. This enables enhanced detection, classification and characterization of focal liver lesions, as well as improved assessment of liver function in diffuse liver diseases. Gadoxetate-enhanced liver MRI is most commonly used for clinical diagnosis of hepatocellular carcinoma, classification of focal liver lesions and cirrhotic nodules [109], but also is used in a large number of further conditions [110]. The possibility to distinguish between benign and malignant liver tumors, due to differences in accumulation of gadoxetate in hepatocytes, allows imaging based 
formulation of the therapeutic strategy $[110,111]$. For instance, hemangiomas and focal nodular hyperplasia do not require any therapeutic intervention, whereas adenomas possess a risk for malignant transformation, and therefore require treatment [112]. Dynamic hepatocyte contrast enhanced MRI is a valuable tool for the assessment of liver volume and liver functional capacity in patients with primary sclerosing cholangitis [113]. Gadoxetate uptake and enhancement in patients with diffuse chronic liver disease is generally lower than in healthy individuals, due to differences in transporter number or activity. Therefore it allows differentiation between two subgroups of nonalcoholic fatty liver disease, plus between simple steatosis and nonalcoholic steatohepatitis [114]; and also can be used for assessment and staging of fibrosis [76] and cirrhosis [115], as well as in predicting liver transplant graft survival [116]. In addition, gadoxetate enhanced MR imaging together with T2-weighted MR cholangiography may be a useful tool in providing information about the biliary system, like biliary injury, bile duct obstruction, diagnosis of cholecystitis, and differentiation of biliary from extrabiliary lesions [117, 118].

Hepatocellular uptake of gadoxetate from blood is mediated in humans by the sinusoidal solute carriers OATP1B1, OATP1B3, and NTCP [119]. Its active secretion into bile in rats is via the apical transporter Mrp2 [120] and it is presumed that the human ortholog (MRP2) mediates its biliary excretion in humans. The extensive biliary clearance of gadoxetate (healthy human: $50 \%$ of administered dose [101]) facilitates its use for evaluation of hepatobiliary transporter inhibition by drugs as a DILI risk factor [32, 33]. This aspect is discussed further in the next section. In addition, gadoxetate-enhanced MRI was successful in prediction of hyperbilirubinemia which occurred during treatment of hepatitis $\mathrm{C}$ patients with a triple therapy of simeprevir, pegylated interferon plus ribavirin [121]. Simeprevir is a substrate of the same transporters for hepatic uptake and excretion as gadoxetate [121]. In rats, a transient impairment of bile flow induced with a single dose of estradiol-17 $\mathrm{D}$-glucuronide was associated with a sixfold decrease in gadoxetate elimination rate [122]. Prednisolone, doxorubicin hydrochloride, cisplatin, and propranolol hydrochloride can lead to a slight but significant increase in the hepatic MRI enhancement observed following administration of gadoxetate to rats, most likely due to the longer retention of the contrast agent in hepatocytes because of its competition with these drugs for biliary excretion into the bile duct [123].

5.2 Effects

on Gadoxetate Hepatic

Clearance of an Investigational Drug Which Cause DILI in Rats
The investigational drug used in these studies [33] is a chemokine receptor antagonist (CKA) whose intended clinical use was in the treatment of systemic inflammatory diseases. Livers from rats dosed orally with the compound for 7 days exhibited dose dependent centrilobular degeneration and necrosis, which was accompanied by neutrophil infiltration and associate sinusoidal congestion. These 
abnormalities in liver histopathology were accompanied by marked elevations in plasma levels of alanine aminotransferase activity, bilirubin and bile acids, which also exhibited clear dose dependency. In vitro studies revealed that the CKA was a potent inhibitor of human OATPIBI $\left(\mathrm{IC}_{50}<3 \mu \mathrm{M}\right)$, plus a less potent inhibitor of both rat $\operatorname{Mrp} 2\left(\mathrm{IC}_{50} 69 \mu \mathrm{M}\right)$ and rat BSEP $\left(\mathrm{IC}_{50} 130 \mu \mathrm{M}\right)$.

To investigate whether these in vitro findings might have in vivo functional relevance, anaesthetized rats were given either a single dose of gadoxetate alone, or CKA plus gadoxetate, then were evaluated by DCE-MRI [33]. Imaging data are shown in Fig. 4. The data were quantified following development of a nonlinear two-compartment model. This provided a good description of gadoxetate disposition in animals dosed with the contrast agent alone, and yielded a rate constant for its hepatic uptake and Michaelis-Menten constants $\left(K_{\mathrm{m}}\right.$ and $\left.V_{\max }\right)$ for biliary secretion. Coadministration of the CKA with gadoxetate resulted in marked inhibition of the rate of hepatic uptake of gadoxetate, plus resulted in a reduced $V_{\max }$ and increased $K_{\mathrm{m}}$ for biliary gadoxetate excretion. These effects were dose dependent and correlated well with the abnormalities in plasma bilirubin and bile acids observed in rats dosed for multiple days with the CKA.

These findings suggest that gadoxetate DCE-MRI can characterize functional consequences in vivo of compounds that perturb hepatobiliary transporters. Furthermore, since gadoxetate is

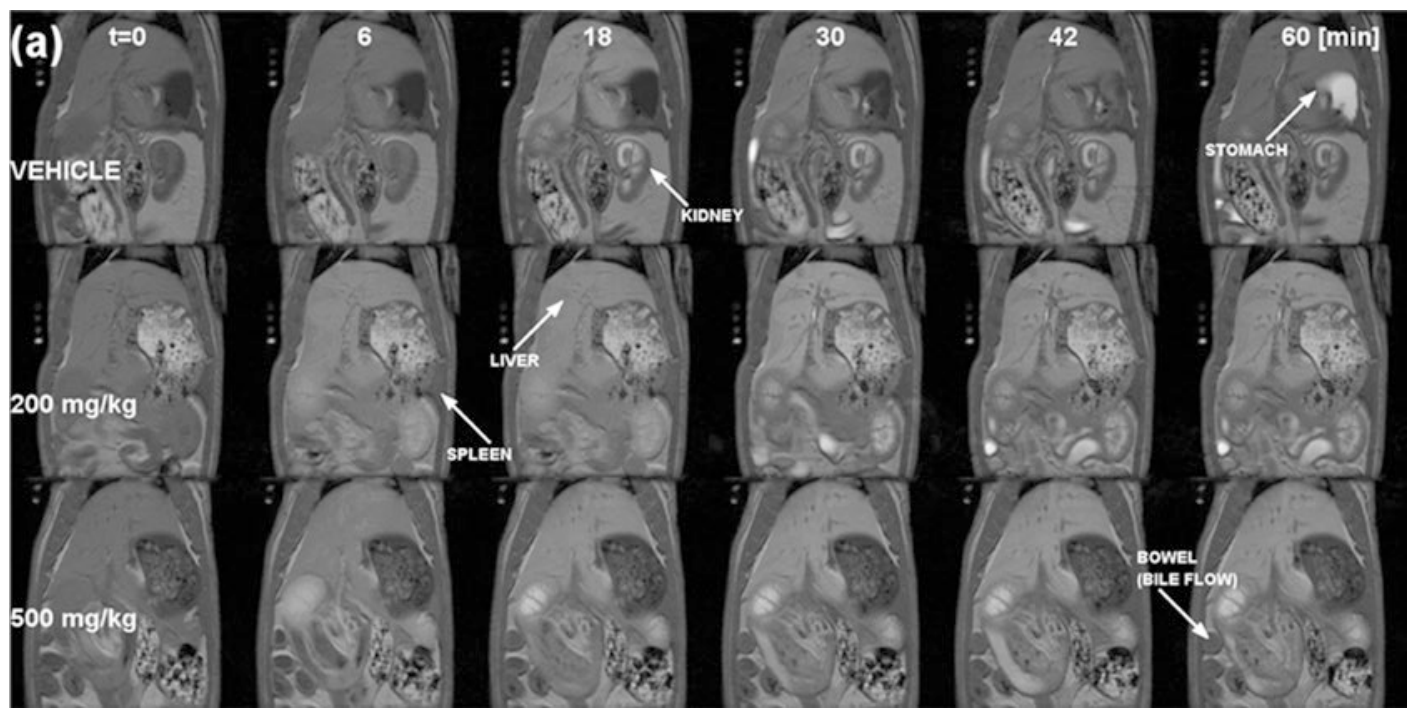

Fig. 4 Examples of dynamic images for animals treated with vehicle (top), $200 \mathrm{mg} / \mathrm{kg}$ (middle) or $500 \mathrm{mg} / \mathrm{kg}$ (bottom) CKA at $t=0,6,18,30,42$, and 60 min after contrast injection. Note the enhancement of the small bowel lumen at about $30 \mathrm{~min}$ after contrast injection and also the reflux of gadoxetate into the stomach at the end of the acquisition in the vehicle treated animal. No enhancement was observed in the bowel of the animal treated with $500 \mathrm{mg} / \mathrm{kg}$ CKA. From [33]. Reproduced by permission of John Wiley \& Sons 
already used clinically to aid the assessment and management of liver disease in patients, this may be a translatable biomarker that can aid human risk assessment of new investigational drugs during clinical trials [33].

\section{Future Opportunities and Challenges}

Many different imaging methodologies and probe substrates have been used to explore processes in the liver that may be relevant to DILI. These methods could provide important additional tools to detect and investigate DILI, and to gain new insight into underlying mechanisms and susceptibility factors.

An especially promising method is gadoxetate DCE-MRI. This is due to the current widespread use of MRI in human liver disease diagnosis and management, plus the very promising data already obtained in rats dosed with an investigational drug that inhibited several hepatobiliary transporters and caused liver injury [33] (see Sect. 5). Nonetheless, substantial further work is required to develop and validate the use of gadoxetate DCE-MRI for DILI risk assessment in animals, and also as a translational biomarker technology that can be used during clinical trials. It is intended that the necessary additional work will be undertaken as part of the TRISTAN project, which is a large collaborative public-private partnership that is cofunded jointly by the European Union and industry via the Innovative Medicines Initiative [124]. The TRISTAN project will also investigate the potential value of gadoxetate DCE-MRI for the assessment of undesired and clinically important drug-drug interactions that occur via hepatobiliary transporter perturbations (see Sect. 4).

A limitation of gadoxetate DCE-MRI is that, since gadoxetate is not transported by BSEP, it does not enable direct investigation of drug-induced inhibition of BSEP activity, which is considered to play an important role in DILI caused by many drugs [11]. Other probe substrates that are transported by BSEP, and ideally are BSEP-specific, are needed. The chemistries described in Sect. 2 might provide compounds suitable for this purpose. Imaging studies undertaken using a BSEP probe substrate could improve our understanding the in vivo significance of in vitro BSEP inhibition data, and in particular the relationship between BSEP inhibition and DILI.

The present chapter covers hepatobiliary transporter interactions, and their role in DILI and drug-drug interactions. Imaging probes and technologies that evaluate other processes relevant to DILI would be complementary. Processes meriting particular attention include oxidative stress and inflammation, in view of their known role in DILI pathogenesis $[1,9]$. 


\section{Acknowledgment}

Preparation of this chapter was funded by the Innovative Medicines Initiative 2 Joint Undertaking, Grant Agreement number 116106-IB4SD-TRISTAN.

\section{References}

1. Leise MD, Poterucha JJ, Talwalkar JA (2014) Drug-induced liver injury. Mayo Clinic Proc 89:95-106

2. Regev A (2014) Drug-induced liver injury and drug development: industry perspective. Semin Liver Dis 34:227-239

3. Waring MJ, Arrowsmith J, Leach AR, Leeson PD, Mandrell S, Owen RM, Pairaudeau G, Pennie WD, Pickett SD, Wang J, Wallace O, Weir A (2015) An analysis of the attrition of drug candidates from four major pharmaceutical companies. Nat Rev Drug Discov $14: 475-486$

4. Chen M, Vijay V, Shi Q, Liu Z, Fang H, Tong W (2011) FDA-approved drug labeling for the study of drug-induced liver injury. Drug Discov Today 16:697-703

5. Onakpoya IJ, Heneghan CJ, Aronson JK (2016) Post-marketing withdrawal of 462 medicinal products because of adverse drug reactions: a systematic review of the world literature. BMC Med 14:10. https://doi. org/10.1186/s12916-016-0553-2

6. Thompson RA, Isin EM, Li Y, Weaver R, Weidolf L, Wilson I, Claesson A, Page K, Dolgos H, Kenna JG (2011) Risk assessment and mitigation strategies for reactive metabolites in drug discovery and development. Chem Biol Interact 192:65-71

7. Thompson RA, Isin EM, Li Y, Weidolf L, Page K, Wilson I, Swallow S, Middleton B, Stahl S, Foster AJ, Dolgos H, Weaver R, Kenna JG (2012) In vitro approach to assess the potential for risk of idiosyncratic adverse reactions caused by candidate drugs. Chem Res Toxicol 25:1616-1632

8. Aleo MD, Luo Y, Swiss R, Bonin PD, Potter DM, Will Y (2014) Human drug-induced liver injury severity is highly associated with dual inhibition of liver mitochondrial function and bile salt export pump. Hepatology 60:1015-1022

9. Ju C, Reilly T (2012) Role of immune reactions in drug-induced liver injury (DILI). Drug Metab Rev 44:107-115

10. Taplin GV, Meredith OM Jr, Kade H (1955) The radioactive ( $\mathrm{I}^{131}$ tagged) rose bengal uptake-excretion test for liver function using external gamma-ray scintillation counting techniques. J Lab Clin Med 45:665-678

11. Kenna JG (2014) Current concepts in drug-induced bile salt export pump (BSEP) interference. Curr Protoc Toxicol 61:23.7.1-23.715

12. Chen R, Wang J, Tang S, Zhang Y, Lv X, Wu S, Yang Z, Xia Y, Chen D, Zhan S (2016) Role of polymorphic bile salt export pump (BSEP, ABCB 11) transporters in anti-tuberculosis drug-induced liver injury in a Chinese cohort. Sci Rep 6:27750. https://doi.org/10.1038/ srep 27750

13. Flower MA (2012) Webb's physics of medical imaging, 2nd edn. CRC, UK. ISBN: 9780750305730

14. Waterton JC (2011) Medical imaging: overview and the importance of contrast. In: Braddock $M$ (ed) biomedical imaging: the chemistry of labels, probes and contrast agents. RSC Press, Cambridge, UK. ISBN: 978-1-84973-014-3, pp 1-20. https://doi. org/10.1039/9781849732918-00001

15. Freeman LM, Lan JA (1990) Radiopharmaceutical evaluation of the hepatobiliary pathway. Int J Rad Appl Instrum B 17:129-139

16. Ziessman HA (2014) Hepatobiliary scintigraphy in 2014. J Nucl Med 55:967-975

17. Geisel D, Lüdemann L, Hamm B, Denecke T (2015) Imaging-based liver function testspast, present and future. Fortschr Röntgenstr 187:863-871

18. Hoekstra LT, de Graaf W, Nibourg GA, Heger M, Bennink RJ, Stieger B, van Gulik TM (2014) Physiological and biochemical basis of clinical liver function tests: a review. Ann Surg 257(1):27-36

19. Yeh BM, Liu PS, Soto JA, Corvera CA, Hussain HK (2009) MR imaging and CT of the biliary tract. Radiographics 29:1669-1688

20. Miller GA, Yeh BM, Breiman RS, Roberts JP, Qayyum A, Coakley FV (2004) Use of CT cholangiography to evaluate the biliary tract after liver transplantation: initial experience. Liver Transpl 10:1065-1070

21. Stockberger SM, Sherman S, Kopecky KK (1996) Helical CT cholangiography. Abdom Imaging 21:98-104 
22. Cabada Giadás T, Sarría Octavio de Toledo L, Martínez-Berganza Asensio MT, Cozcolluela Cabrejas R, Alberdi Ibáñez I, Alvarez López A, García-Asensio S (2002) Helical CT cholangiography in the evaluation of the biliary tract: application to the diagnosis of choledocholithiasis. Abdom Imaging 27:61-70

23. Frimmer M, Giessen FRG (1988) The transport of bile acids in liver cells. Biochim Biophys Acta 947:75-99

24. Hargreaves T, Lathe GH (1963) Inhibitory aspects of bile secretion. Nature 200:1172-1176

25. FDA (2015) NDA 09-321; Cholografin ${ }^{\circledR}$ Meglumine (Iodipamide Meglumine Injection USP 52\%). http://www. accessdata.fda.gov/drugsatfda_docs / label/2015/009321s028lbl.pdf. Accessed 4 April 2017

26. Bayer (2007) Product information Biliscopin ${ }^{\circledR}$ for infusion. http://www.bayerresources. com.au/resources/uploads/PI/file9317. pdf. Accessed 4 April 2017

27. MHRA (2016) Summary of product characteristics: Primovist $0.25 \mathrm{mmol} / \mathrm{ml}$, solution for injection, prefilled syringe https://www. medicines.org.uk/emc/medicine/15927. Accessed 4 April 2017

28. FDA (2013) Highlights of prescribing information MultiHance (gadobenate dimeglumine) injection. https://www.accessdata.fda. gov/drugsatfda_docs/label/2013/02135 7s013,021358s012lbl.pdf. Accessed 4 April 2017

29. Hamm B, Staks T, Muhler A, Bollow M, Taupitz M, Frenzel T, Wolf KJ, Weinmann HJ, Lange L (1995) Phase I clinical evaluation of Gd-EOB-DTPA as a hepatobiliary MR contrast agent: safety, pharmacokinetics, and MR imaging. Radiology 195:785-792

30. Nassif A, Jia J, Keiser M, Oswald S, Modess C, Nagel S, Weitschies W, Hosten N, Siegmund W, Kühn JP (2012) Visualization of hepatic uptake transporter function in healthy subjects by using gadoxetic acid-enhanced MR imaging. Radiology 264:741-750

31. Jia J, Puls D, Oswald S, Jedlitschky G, Kühn JP, Weitschies W, Hosten N, Siegmund W, Keiser M (2014) Characterization of the intestinal and hepatic uptake/efflux transport of the magnetic resonance imaging contrast agent gadolinium-ethoxylbenzyldiethylenetriamine-pentaacetic acid. Investig Radiol 49(2):78-86

32. Georgiou L, Penny J, Nicholls G, Woodhouse N, Blé F-X, Hubbard Cristinacce PL, Naish JH (2017) Quantitative assessment of liver function using Gadoxetate-enhanced magnetic resonance imaging: monitoring transporter-mediated processes in healthy volunteers. Investig Radiol 52:111-119

33. Ulloa JL, Stahl S, Yates J, Woodhouse $\mathrm{N}$, Kenna JG, Jones HB, Waterton JC, Hockings PD (2013) Assessment of gadoxetate DCE-MRI as a biomarker of hepatobiliary transporter inhibition. NMR Biomed 26:1258-1270

34. Gallez B, Bacic G, Swartz HM (1996) Evidence for the dissociation of the hepatobiliary MRI contrast agent Mn-DPDP. Magn Reson Med 35:14-19

35. Gallez B, Baudelet C, Adline J et al (1996) The uptake of Mn-DPDP by hepatocytes is not mediated by the facilitated transport of pyridoxine. Magn Reson Imaging 14:1191-1195

36. Nunn AD, Loberg MD (1981) Hepatobiliary agents. In: Spencer RD (ed) Radiopharmaceuticals: structure activity relationships. Grune \& Stratton, New York

37. Bracco (2014) Choletec $^{\circledR}$ kit for the preparation of technetium $\mathrm{Tc} 99 \mathrm{~m}$ mebrofenin. http://imaging.bracco.com/sites/braccoimaging.com/files/technica_sheet_pdf/ Choletec Prescribing Information.pdf. Accessed 4 April 2017

38. Pharmalucence (2008) Hepatolite ${ }^{\circledR}$ kit for the preparation of technetium $\mathrm{Tc} 99 \mathrm{~m}$ disofenin for injection. http://www.pharmalucence. com/images/HepatoliteInsert.pdf. Accessed 4 April 2017

39. Baker RJ, Bellen JC, Ronai PM (1975) Technetium 99m-pyridoxylideneglutamate: a new hepatobiliary radiopharmaceutical. I. Experimental aspects. J Nucl Med 16:720-727

40. Kato-Azuma M (1982) Tc-99m(Sn)-NPyridoxylaminates: a new series of hepatobiliary imaging agents. J Nucl Med 23:517-552

41. Fritzberg AR, Bloedow DC, Estima D, Johnson DL (1984) Comparison of $99 \mathrm{mTc}-\mathrm{N}$ - pyridoxyl- 5 - methyltryptophan and 99mTc-N-3(-bromo-2,4,6trimethylacetanilide)-iminodiacetate as hepatobiliary radiopharmaceuticals. J Pharm Sci 73:1861-1863

42. Kobayashi M, Nakanishi T, Nishi K, Higaki Y, Okudaira H, Ono M, Tsujiuchi T, Mizutani A, Nishii R, Tamai I, Arano Y, Kawai K (2014) Transport mechanisms of hepatic uptake and bile excretion in clinical hepatobiliary scintigraphy with $99 \mathrm{mTc}-\mathrm{N}$-pyridoxyl5-methyltryptophan. Nucl Med Biol 41:338-342. https://doi.org/10.1016/j. nucmedbio.2014.01.004 
43. Ghibellini G, Leslie EM, Pollack GM, Brouwer KL (2008) Use of tc-99m mebrofenin as a clinical probe to assess altered hepatobiliary transport: integration of in vitro, pharmacokinetic modeling, and simulation studies. Pharm Res 25:1851-1860

44. Neyt S, Huisman MT, Vanhove C, De Man $\mathrm{H}$, Vliegen M, Moerman L, Dumolyn C, Mannens G, De Vos F (2013) In vivo visualization and quantification of (disturbed) Oatpmediated hepatic uptake and Mrp2-mediated biliary excretion of $99 \mathrm{mTc}$-mebrofenin in mice. J Nucl Med 54:624-630

45. de Graaf W, Häusler S, Heger $M$, van Ginhoven TM, van Cappellen G, Bennink RJ, Kullak-Ublick GA, Hesselmann R, van Gulik TM, Stieger B (2011) Transporters involved in the hepatic uptake of $(99 \mathrm{~m}) \mathrm{Tc}$-mebrofenin and indocyanine green. J Hepatol 54:738-745

46. Swift B, Yue W, Brouwer KL (2010) Evaluation of (99m)technetium-mebrofenin and $(99 \mathrm{~m})$ technetium-sestamibi as specific probes for hepatic transport protein function in rat and human hepatocytes. Pharm Res 27:1987-1998

47. Satoh K, Yamamoto Y, Nishiyama Y, Wakabayashi H, Ohkawa M (2003) 99mTcGSA liver dynamic SPECT for the preoperative assessment of hepatectomy. Ann Nucl Med 17:61-67

48. Wadas TJ, Sherman CD, Miner JH, Duncan JR, Anderson CJ (2010) The biodistribution of $[153 \mathrm{Gd}] \mathrm{Gd}$-labeled magnetic resonance contrast agents in a transgenic mouse model of renal failure differs greatly from control mice. Magn Reson Med 64(5):1274-1280

49. Traxl A, Wanek T, Mairinger S, Stanek J, Filip T, Sauberer M, Müller M, Kuntner C, Langer $O$ (2015) Breast cancer resistance protein and P-glycoprotein influence in vivo disposition of 11C-Erlotinib. J Nucl Med 56:1930-1936. https://doi.org/10.2967/ jnumed.115.161273

50. Hume WE, Shingaki T, Takashima T, Hashizume Y, Okauchi T, Katayama Y, Hayashinaka E, Wada Y, Kusuhara $\mathrm{H}$, Sugiyama Y, Watanabe Y (2013) The synthesis and biodistribution of [11C]metformin as a PET probe to study hepatobiliary transport mediated by the multi-drug and toxin extrusion transporter l (MATEl) in vivo. Bioorg Med Chem 21:7584-7590

51. He J, Yu Y, Prasad B, Link J, Miyaoka RS, Chen X, Unadkat JD (2014) PET imaging of Oatp-mediated hepatobiliary transport of [11C]rosuvastatin in the rat. Mol Pharmacol 11:2745-2754. https://doi.org/10.1021/ mp500027c.
52. Shingaki T, Takashima T, Ijuin R, Zhang $\mathrm{X}$, Onoue $\mathrm{T}$, Katayama $\mathrm{Y}$, Okauchi T, Hayashinaka E, Cui Y, Wada Y, Suzuki M, Maeda K, Kusuhara H, Sugiyama Y, Watanabe Y (2013) Evaluation of Oatp and Mrp2 activities in Hepatobiliary excretion using newly developed positron emission tomography tracer [11C]dehydropravastatin in rats. J Pharmacol Exp Ther 347:193-202

53. Takashima T, Hashizume Y, Katayama Y, Murai M, Wada Y, Maeda K, Sugiyama Y, Watanabe Y (2011) The involvement of organic anion transporting polypeptide in the hepatic uptake of telmisartan in rats: PET studies with $\left[{ }^{11} \mathrm{C}\right]$ telmisartan. Mol Pharmacol 8:1789-1798

54. Takashima-Hirano M, Takashima T, Katayama Y, Wada Y, Sugiyama Y, Watanabe Y, Doi H, Suzuki M (2011) Efficient sequential synthesis of PET probes of the COX-2 inhibitor [11C]celecoxib and its major metabolite [11C]SC-62807 and in vivo PET evaluation. Bioorg Med Chem 19:2997-3004

55. Takashima T, Wu C, Takashima-Hirano M, Katayama Y, Wada Y, Suzuki M, Kusuhara H, Sugiyama Y, Watanabe Y (2013) Evaluation of breast cancer resistance protein function in hepatobiliary and renal excretion using PET with 11C-SC-62807. J Nucl Med 54:267

56. Sørensen M, Munk OL, Ørntoft NW, Frisch K, Andersen KJ, Mortensen FV, Alstrup AK, Ott P, Hofmann AF, Keiding $S$ (2016) Hepatobiliary secretion kinetics of conjugated bile acids measured in pigs by 11C-cholylsarcosine PET. J Nucl Med 57:961-966

57. Ørntoft NW, Munk OL, Frisch K, Ott P, Keiding S, Sørensen M (2017) Hepatobiliary transport kinetics of the conjugated bile acid tracer 11C-CSar quantified in healthy humans and patients by positron emission tomography (PET). J Hepatol S0168-8278(17):30120-30124

58. Zinchunk V, Zinchuk O, Okada T (2005) Experimental LPS-induced cholestasis alters subcellular distribution and affects colocalization of Mrp2 and Bsep proteins: a quantitative colocalization study. Microsc Res Tech 67:65-70

59. Hammad S, Hoehme S, Friebel A, von Recklinghausen I, Othman A, Begher-Tibbe B, Reif R, Godoy P, Johann T, Vartak A, Golka K, Bucur PO, Vibert E, Marchan R, Christ B, Dooley S, Meyer C, Ilkavets I, Dahmen U, Dirsch O, Böttger J, Gebhardt R, Drasdo D, Hengstler JG (2014) Protocols for staining of bile canalicular and sinusoidal networks of human, mouse and pig livers, three-dimensional reconstruction and 
quantification of tissue microarchitecture by image processing and analysis. Arch Toxicol 88:1161-1183

60. de Waart DR, Häusler S, Vlaming ML, Kunne C, Hänggi E, Gruss HJ, Oude Elferink RP, Stieger B (2010) Hepatic transport mechanisms of cholyl-L-lysyl-fluorescein. J Pharmacol Exp Ther 334:78-86

61. Milkiewicz P, Mils CO, Huscher SG, Cardenas R, Cardenas T, Williams A, Elias E (2001) Visualization of the transport of primary and secondary bile acids across liver tissue in rats: in vivo study with fluorescent bile acids. J Hepatol 34:4-10

62. Milkiewicz P, Roma MG, Elias E, Coleman R (2002) Hepatoprotection with tauroursodeoxycholate and beta muricholate against taurolithocholate induced cholestasis: involvement of signal transduction pathways. Gut 51:113-119

63. Barber JA, Stahl SH, Summers C, Barrett G, Park BK, Foster JR, Kenna JG (2015) Quantification of drug-induced inhibition of canalicular cholyl-1-lysyl-fluorescein excretion from hepatocytes by high content cell imaging. Toxicol Sci 148(1):48-59

64. Milkiewicz P, Saksena S, Cardenas T, Mills CO, Elias E (2000) Plasma elimination of cholyl-lysyl-fluorescein (CLF): a pilot study in patients with liver cirrhosis. Liver 20:330-334

65. Ryan JC, Dunn KW, Decker BS (2014) Effects of chronic kidney disease on liver transport: quantitative intravital microscopy of fluorescein transport in the rat liver. Am J Physiol Regul Integr Comp Physiol 307:Rl488-R1492

66. De Bruyn T, Fattah S, Stieger B, Augustijns P, Annaert P (2011) Sodium fluorescein is a probe substrate for hepatic drug transport mediated by OATP1Bl and OATP1B3. J Pharm Sci 100:5018-5032

67. De Bruyn T, Sempels W, Snoeys J, Holmstock $\mathrm{N}$, Chatterjee S, Stieger B, Augustijns P, Hofkens J, Mizuno H, Annaert P (2014) Confocal imaging with a fluorescent bile acid analogue closely mimicking hepatic taurocholate disposition. J Pharm Sci 103:1872-1881

68. Reif R, Karlsson J, Günther G, Beattie L, Wrangborg D, Hammad S, Begher-Tibbe B, Vartak A, Melega S, Kaye PM, Hengstler JG, Jirstrand M (2015) Bile canalicular dynamics in hepatocyte sandwich cultures. Arch Toxicol 89:1861-1870

69. Nakanishi $T$, Ikenaga $M$, Fukuda $H$, Matsunaga N, Tamai I (2012) Application of quantitative time-lapse imaging (QTLI) for evaluation of Mrp2-based drug-drug inter- action induced by liver metabolites. Toxicol Appl Pharmacol 263:244-250

70. Burbank MG, Burban A, Sharanek A, Weaver RJ, Guguen-Guillouzo C, Guillouzo A (2016) Early alterations of bile canaliculi dynamics and the rho kinase/myosin light chain kinase pathway are characteristics of drug-induced intrahepatic cholestasis. Drug Metabol Dispos 44:1780-1793

71. Feng HL, Li Q, Wang L, Yuan GY, Cao WK (2014) Indocyanine green clearance test combined with MELD score in predicting the short-term prognosis of patients with acute liver failure. Hepatobiliary Pancreat Dis Int 13:271-275

72. Schreiter T, Sowa JP, Schlattjan M, Treckmann J, Andreas P, Strucksberg KH, Baba HA, Odenthal M, Gieseler RK, Gerken G, Arteel GE, Canbay A (2016) Human ex-vivo liver model for acetaminophen-induced liver damage. Sci Rep 23(6):1-10

73. https://www.accessdata.fda.gov/drugsatfda_docs/label/2006/011525s017lbl.pdf

74. Ingrisch $M$, Sourbron S (2013) Tracer-kinetic modeling of dynamic contrast-enhanced MRI and CT: a primer. J Pharmacokinet Pharmacodyn 40:281-300

75. Giraudeau C, Leporq B, Doblas S, Lagadec M, Pastor CM, Daire J-L, Van Beers BE (2017) Gadoxetate-enhanced MR imaging and compartmental modelling to assess hepatocyte bidirectional transport function in rats with advanced liver fibrosis. Eur Radiol 27:1804-1811

76. Juluru K, Talal AH, Yantiss RK, Spincemaille P, Weidman EK, Giambrone AE, Jalili S, Sourbron SP, Dyke JP (2017) Diagnostic accuracy of intracellular uptake rates calculated using dynamic Gd-EOB-DTPAenhanced MRI for hepatic fibrosis stage. J Magn Reson Imaging 45:1177-1185

77. Lagadec M, Doblas S, Giraudeau C, Ronot M, Lambert SA, Fasseu M, Paradis V, Moreau R, Pastor CM, Vilgrain V, Daire JL, Van Beers BE (2015) Advanced fibrosis: correlation between pharmacokinetic parameters at dynamic gadoxetate-enhanced MR imaging and hepatocyte organic anion transporter expression in rat liver. Radiology 274:379-386

78. Sourbron S, Sommer WH, Reiser MF, Zech CJ (2012) Combined quantification of liver perfusion and function with dynamic Gadoxetic acid-enhanced MR imaging. Radiology 263:874-883

79. Liver Imaging Reporting and Data System (LI-RADS). American College of Radiology website. www.acr.org/Quality-Safety/ 
Resources/LIRADS. Accessed l April 2013. http://www.ajronline.org/doi/ full/10.2214/AJR.12.9491

80. Tamada $\mathrm{T}$, Ito $\mathrm{K}$, Higaki $\mathrm{A}$, Yoshida $\mathrm{K}$, Kanki A, Sato T, Higashi H, Sone T (2011) Gd-EOB-DTPA-enhanced MR imaging: evaluation of hepatic enhancement effects in normal and cirrhotic livers. Eur J Radiol 80(3):e311-e316

81. Watanabe T, Kusuhara H, Maeda K, Shitara Y, Sugiyama Y (2009) Physiologically based pharmacokinetic modeling to predict transporter-mediated clearance and distribution of pravastatin in humans. J Pharmacol Exp Ther 328:652-662

82. Chu X, Korzekwa K, Elsby R, Fenner K, Galetin A, Lai Y, Matsson P, Moss A, Nagar S, Rosania GR, Bai JP, Polli JW, Sugiyama $\mathrm{Y}$, Brouwer KL, International Transporter Consortium (2013) Intracellular drug concentrations and transporters: measurement, modeling and implications in the liver. Clin Pharmacol Ther 94:126-141

83. International Transporter Consortium, Giacomini KM, Huang SM, Tweedie DJ, Benet LZ, Brouwer KL, Chu X, Dahlin A, Evers R, Fischer V, Hillgren KM, Hoffmaster KA, Ishikawa T, Keppler D, Kim RB, Lee CA, Niemi M, Polli JW, Sugiyama Y, Swaan PW, Ware JA, Wright SH, Yee SW, ZamekGliszczynski MJ, Zhang L (2010) Membrane transporters in drug development. Nat Rev Drug Discov 9:215-236

84. FDA (2012) FDA Guidance for industry 2012, drug interaction studies-study design, data analysis, implications for dosing, and labeling recommendations. https://www. fda.gov/downloads/Drugs/Guidances/ ucm292362.pdf

85. Zamek-Gliszczynski MJ, Chu X, Polli JW, Paine MF, Galetin A (2014) Understanding the transport properties of metabolites: case studies and considerations for drug development. Drug Metab Dispos 42:650-664

86. European Medicines Agency (2012) Guideline on the investigation of drug interactions. EMA website [online]: http://www. ema.europa.eu

87. Zamek-Gliszczynski MJ, Hoffmaster KA, Tweedie DJ, Giacomini KM, Hillgren KM (2012) Highlights from the international transporter consortium second workshop. Clin Pharmacol Ther 92:553-556

88. Hibma JE, Zur AA, Castro RA, Wittwer MB, Keizer RJ, Yee SW, Goswami S, Stocker SL, Zhang X, Huang Y, Brett CM, Savic RM, Giacomini KM (2016) The effect of famotidine, a MATEl-selective inhibitor, on the pharmacokinetics and pharmacodynamics of metformin. Clin Pharmacokinet 55:711-721

89. Brouwer KL, Keppler D, Hoffmaster KA, Bow DA, Cheng Y, Lai Y, Palm JE, Stieger $B$, Evers R, International Transporter Consortium (2013) In vitro methods to support transporter evaluation in drug discovery and development. Clin Pharmacol Ther 94:95-112

90. Vivares A, Salle-Lefort S, Arabeyre-Fabre C, Ngo R, Penarier G, Bremond M, Moliner P, Gallas JF, Fabre G, Klieber S (2015) Morphological behaviour and metabolic capacity of cryopreserved human primary hepatocytes cultivated in a perfused multiwell device. Xenobiotica 45:29-44

91. Galetin A (2014) Rationalizing underprediction of drug clearance from enzyme and transporter kinetic data: from in vitro tools to mechanistic modeling. Methods Mol Biol 1113:255-288

92. Ménochet K, Kenworthy KE, Houston JB, Galetin A (2012) Use of mechanistic modelling to assess inter-individual variability and inter-species differences in active uptake in human and rat hepatocytes. Drug Metab Dispos 40:1744-1756

93. Zamek-Gliszczynski MJ, Lee CA, Poirier A, Bentz J, Chu X, Ellens H, Ishikawa T, Jamei M, Kalvass JC, Nagar S, Pang KS, Korzekwa K, Swaan PW, Taub ME, Zhao P, Galetin A, International Transporter Consortium (2013) ITC recommendations on transporter kinetic parameter estimation and translational Modeling of transport-mediated PK and DDIs in humans. Clin Pharmacol Ther 94:64-79

94. Jones HM, Barton HA, Lai Y, Bi YA, Kimoto E, Kempshall S, Tate SC, El-Kattan A, Houston JB, Galetin A, Fenner KS (2012) Mechanistic pharmacokinetic modeling for the prediction of transporter-mediated disposition in humans from sandwich culture human hepatocyte data. Drug Metab Dispos 40:1007-1017

95. Tsamandouras N, Dickinson G, Guo Y, Hall S, Rostami-Hodjegan A, Galetin A, Aarons L (2015) Development and application of a mechanistic pharmacokinetic model for simvastatin and its active metabolite simvastatin acid using an integrated population PBPK approach. Pharm Res 32:1864-1883

96. Gertz M, Cartwright CM, Hobbs MJ, Kenworthy KE, Rowland M, Houston JB, Galetin A (2013) Cyclosporine inhibition of hepatic and intestinal CYP3A4, uptake and efflux transporters: application of PBPK modeling in the assessment of 
drug-drug interaction potential. Pharm Res 30:761-780

97. Gertz M, Tsamandouras N, Säll C, Houston JB, Galetin A (2014) Reduced physiologicallybased pharmacokinetic model of repaglinide: impact of OATP1Bl and CYP2C8 genotype and source of in vitro data on the prediction of drug-drug interaction risk. Pharm Res $31: 2367-2382$

98. Jones HM, Chen Y, Gibson C, Heimbach T, Parrott N, Peters SA, Snoeys J, Upreti VV, Zheng M, Hall SD (2015) Physiologically based pharmacokinetic modeling in drug discovery and development: a pharmaceutical industry perspective. Clin Pharmacol Ther 97:247-262

99. Takashima T, Kitamura S, Wada Y, Tanaka $M$, Shigihara $Y$, Ishii $H$, Ijuin $R$, Shiomi $S$, Nakae T, Watanabe Y, Cui Y, Doi H, Suzuki M, Maeda K, Kusuhara H, Sugiyama Y, Watanabe Y (2012) PET imaging-based evaluation of hepatobiliary transport in humans with (15R)-11C-TIC-Me. J Nucl Med 53:741-748

100. Döhr O, Hofmeister R, Treher M, Schweinfurth H (2007) Preclinical safety evaluation of Gd-EOB-DTPA (Primovist). Investig Radiol 42:830-841

101. Reimer P, Rummeny EJ, Shamsi K, Balzer T, Daldrup HE, Tombach B, Hesse T, Berns T, Peters PE (1996) Phase II clinical evaluation of Gd-EOB-DTPA: dose, safety aspects, and pulse sequence. Radiology 199:177-183

102. Breuer J, Balzer T, Shamsi K, Carter R (2003) Clinical safety experience from phase II and III studies of Gd-EOB-DTPA: a new liverspecific MR contrast agent. Europ Radiol 13(Suppl 2):S109. Abstract No 7.05

103. Bluemke DA, Sahani D, Amendola M, Balzer T, Breuer J, Brown JJ, Casalino DD, Davis PL, Francis IR, Krinsky G, Lee FT Jr, Lu D, Paulson EK, Schwartz LH, Siegelman ES, Small WC, Weber TM, Welber A, Shamsi K (2005) Efficacy and safety of MR imaging with liver-specific contrast agent: U.S. multicenter phase III study. Radiology 237:89-98

104. Endrikat J, Kim SY, Sakaguchi T, Dohanish S, Breuer J (2016) Safety of gadoxetate disodium: results from six clinical phase IV studies in 8194 patients. Acta Radiol 57:1326-1333

105. Hope TA, Doherty A, Fu Y, Aslam R, Qayyum A, Brasch RC (2012) Gadolinium accumulation and fibrosis in the liver after administration of gadoxetate disodium in a rat model of active hepatic fibrosis. Radiology 264:423-427

106. Lauenstein T, Ramirez-Garrido F, Kim YH, Rha SE, Ricke J, Phongkitkarun S, Boettcher J, Gupta RT, Korpraphong P, Tanomkiat
W, Furtner J, Liu PS, Henry M, Endrikat J (2015) Nephrogenic systemic fibrosis risk after liver magnetic resonance imaging with gadoxetate disodium in patients with moderate to severe renal impairment: results of a prospective, open-label, multicenter study. Investig Radiol 50:416-422

107. Kahn J, Posch H, Steffen IG, Geisel D, Bauknecht C, Liebig T, Denecke T (2017) Is there long-term signal intensity increase in the central nervous system on Tl-weighted images after MR imaging with the hepatospecific contrast agent Gadoxetic acid? A crosssectional study in 91 patients. Radiology 282:708-716

108. Ichikawa S, Motosugi U, Omiya Y, Onishi H (2017) Contrast agent-induced high signal intensity in dentate nucleus on unenhanced Tl-weighted images: comparison of gadodiamide and gadoxetic acid. Invest Radiol 52(7):389-395. https://doi.org/10.1097/ RLI.0000000000000360. [Epub ahead of print]

109. Neri E, Bali MA, Ba-Ssalamah A, Boraschi P, Brancatelli G, Caseiro Alves F, Grazioli L, Helmberger T, Lee JM, Manfredi R, MartìBonmatì L, Matos C, Merkle EL, Op De Beeck B, Schima W, Skehan S, Vilgrain V, Zech C, Bartolozzi C (2016) ESGAR consensus statement on liver MR imaging and clinical use of liver-specific contrast agents. Eur Radiol 26:921-931

110. Channual S, Pahwa A, DS L, Raman SS (2016) Enhancements in hepatobiliary imaging: the spectrum of gadolinium-ethoxybenzyl diethylenetriaminepentaacetic acid usages in hepatobiliary magnetic resonance imaging. Abdom Radiol 41:1825-1841

111. Suh CH, Kim KW, Kim GY, Shin YM, Kim PN, Park SH (2015) The diagnostic value of Gd-EOB-DTPA-MRI for the diagnosis of focal nodular hyperplasia: a systematic review and meta-analysis. Eur Radiol 25:950-960

112. Doyle M, Bagia JS, Yeo J, Teixeira-Pinto A, Tran S (2016) Differentiation of hepatic adenoma from focal nodular hyperplasia with primovist MRI: validation of diagnostic criteria. HPB 18:e730. https://doi.org/10.1016/j. hpb.2016.01.183

113. Nilsson H, Blomqvist L, Douglas L, Nordell A, Jacobsson H, Hagen K, Bergquist A, Jonas E (2014) Dynamic gadoxetate-enhanced MRI for the assessment of total and segmental liver function and volume in primary sclerosing cholangitis. J Magn Reson Imaging 39:879-886

114. Ba-Ssalamah A, Bastati N, Wibmer A, Fragner R, Hodge JC, Trauner M, Herold CJ, Bashir MR, Van Beers BE (2017) Hepatic gadoxetic 
acid uptake as a measure of diffuse liver disease: where are we? J Magn Reson Imaging 45:646-659

115. Takeyama Y, Tsuchiya N, Kunimoto H, Fukunaga A, Sakurai K, Hirano G, Yokoyama K, Morihara D, Anan A, Irie M, Shakado S, Sohda T, Sakisaka S (2015) Gadoliniumethoxybenzyl-diethylenetriamine pentaacetic acid-enhanced magnetic resonance imaging as a useful detection method for advanced primary biliary cirrhosis. Hepatol Res 45:E108-E1 14

116. Bastati N, Wibmer A, Tamandl D, Einspieler H, Hodge JC, Poetter-Lang S, Rockenschaub S, Berlakovich GA, Trauner M, Herold C, Ba-Ssalamah A (2016) Assessment of orthotopic liver transplant graft survival on gadoxetic acid-enhanced magnetic resonance imaging using qualitative and quantitative parameters. Investig Radiol 51:728-734

117. Lee NK, Kim S, Lee JW, Lee SH, Kang DH, Kim GH, Seo HI (2009) Biliary MR imaging with Gd-EOB-DTPA and its clinical applications. Radiographics 29:1707-1724

118. Blair P, Low G (2014) Biliary anastomotic leakage following orthotopic liver transplant: the use of primovist (gadoxetate disodium) as an intravenous MR cholangiography contrast agent for biliary leakage. J Clin Imaging Sci 4:75

119. Leonhardt M, Keiser M, Oswald S, Kühn J, Jia J, Grube M, Kroemer HK, Siegmund W, Weitschies W (2010) Hepatic uptake of the magnetic resonance imaging contrast agent Gd-EOB-DTPA: role of human organic anion transporters. Drug Metab Dispos 38:1024-1028

120. Saito S, Obata A, Kashiwagi Y, Abe K, Murase K (2013) Dynamic contrast-enhanced MRI of the liver in Mrp2-deficient rats using the hepatobiliary contrast agent Gd-EOBDTPA. Investig Radiol 48:548-553

121. Okubo H, Kitamura T, Ando H, Fukada H, Igusa Y, Kokubu S, Miyazaki A, Fujimura A, Shiina S, Watanabe S (2017) Gadoxetic acid-enhanced MR imaging predicts Simeprevir-induced hyperbilirubinemia during hepatitis $C$ virus treatment: a pilot study. J Clin Pharmacol 57:369-375

122. Ulloa J, Stahl S, Liess C, Bright J, McDermott A, Woodhouse N, Halliday J, Parmar A, Healing G, Kenna JG, Holmes AP, Barjat H, Waterton JC, Hockings PD (2010) Effects of a single intravenous dose of Estradiol-17? D-Glucuronide on biliary excretion: assessment with Gadoxetate DCEMRI. Procedings of the international society of magnetic resonance in medicine eighteenth scientific meeting and exhibition, Stockholm, Sweden, 2593

123. Kato N, Yokawa T, Tamura A, Heshiki A, Ebert W, Weinmann HJ (2002) Gadoliniumethoxybenzyl-diethylenetriamine-pentaacetic acid interaction with clinical drugs in rats. Investig Radiol 37:680-684

124. http://www.eortc.org/news/new-tristanproject-leverages-potential-of-imaging-techniques-in-drug-safety-assessment/

Open Access This chapter is licensed under the terms of the Creative Commons Attribution 4.0 International License (http://creativecommons.org/licenses/by/4.0/), which permits use, sharing, adaptation, distribution and reproduction in any medium or format, as long as you give appropriate credit to the original author(s) and the source, provide a link to the Creative Commons license and indicate if changes were made.

The images or other third party material in this chapter are included in the chapter's Creative Commons license, unless indicated otherwise in a credit line to the material. If material is not included in the chapter's Creative Commons license and your intended use is not permitted by statutory regulation or exceeds the permitted use, you will need to obtain permission directly from the copyright holder.

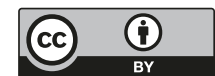

